\title{
Some uses and abuses of electrodermal measures
}

\author{
JOHN J. FUREDY, Univensity of Toronto, \\ Toronto 5, Canada
}

In replying to Fried et al's comments (1967c) on a criticism (Furedy, 1968) of one aspect of their work, a more extensive examination is presented of their use of electrodermal levels and changes in levels as dependent variables for studying such phenomena as adaptation, conditioning, anxiety, novelty, and the orienting response in five recent reports. This broader look reveals a number of conceptual and factual inadequacies in the electrodermal measurement techniques of these investigator.

In another journal (Furedy, 1968) I presented and interpreted electrodermal data to indicate that the appropriate dependent variable for studying "the rapid changes which result from stimulation" (Woodworth \& Schlosberg, 1954, p. 137) is that of transient electrodermal changes in levels (ECL) rather than the more permanent variations in basal electrodermal levels (EL). The reason for emphasizing this bit of orthodoxy was to indicate that certain startling claims about novelty and the GSR in two recent papers in that journal by Fried and his associates (Fried, Korn, \& Welch, 1966a; Fried, Welch, Friedman, \& Gluck, 1967a) were due to measurement error involving an inappropriate use of EL. A paper in this journal by Fried, Friedman, \& Welch $(1967 \mathrm{c})$ suggests that they have not fully appreciated Woodworth and Schlosberg's point concerning the conditions under which ECL, rather than $E L$, is the appropriate dependent variable.

Before reconsidering this question, however, I would first like to examine the particular use that Fried and his associates make of EL to study "adaptation" or variations in "activation level" (Fried et al, 1967 c, p. 635). Basal EL is an appropriate dependent variable for studying such variations "in the general level of activation," as distinct from "the rapid changes resulting from stimulation" (Woodworth \& Schlosberg, 1954, p. 137). Hence, contrary to their impression, Fried et al have not "been taken to task" for adopting this "strategy" (Fried et al, 1967c, p. 635). However, these investigators' specific tactics in using $\mathrm{EL}$ to make assertions about electrodermal adaptation, and such related topics as anxiety and conditioning, in quite a number of published reports (Fried et al, 1966a; Fried, Welch, \& Friedman, 1966b; Fried et al, 1967a; Fried, Welch, Friedman,
\& Gluck, 1967b; Fried et al, 1967c) do warrant further examination.

First, there is the question whether by "adaptation," Fried et al mean a decrease or an increase in EL over time. They adopt the former alternative in four of their five sampled papers (Fried et al, 1966a, 1966b, $1967 \mathrm{a}$, and 1967c) where the claim that adaptation phenomena were obtained is accompanied by graphs showing a decrease in EL over trials. However, in the remaining report, the electrodermal pattern of a "control group" (Fried et al, 1967b, p. 419), which is said to exhibit adaptation, is in fact associated with a graphical increase of EL over trials (Fried et al, 1967b, p. 420).

This conflict is not resolved by a second, more covert, inconsistency in what these investigators use as the measure of EL itself. Thus, while EL is expressed in terms of resistance in four of their reports (Fried et al, 1966a, b, 1967a, b), their last paper expresses EL in units of conductance (Fried et al, 1967c). As resistance and conductance are reciprocally related, the choice between these alternative measures of EL determines whether an EL variation over trials is reported as an increase or a decrease.

If the disparate positions on the definition of adaptation (EL increase rather than EL decrease) and on the measure to be used for EL (conductance rather than resistance) had occurred in the same paper, the basic inconsistency in Fried et al's tactics could readily be eliminated. In that case, for example, a switch to the position they more frequently adopt on the latter question (i.e. resistance rather than conductance as the $\mathrm{EL}$ measure) would also produce uniformity on the former question (i.e., EL decrease as defining adaptation in all five papers). However, since the disparate positions on the two issues of EL measure and adaptation definition appear in two different papers (respectively, Fried et al, 1967c and b), it seems that these investigators have real problems to overcome before they can achieve the internal consistency necessary for an adequate tactical use of $\mathrm{EL}$ as a dependent variable in the study of adaptation phenomena. Moreover, the resolution of these problems is not aided by what seems to be a gross misplacement of the decimal point in the mean conductances reported in these investigators' last paper. The graph for these results indicates mean values ranging between about .25 and .35 mhos (Fried et al, 1967c,p. 636), which implies that their "custom designed constant bridge" was recording mean resistance levels ranging between about 4 and 3 ohms. Such readings may be possible for copper wires, but are rather incredible for college students.

Fried and his associates found my earlier point regarding the strategical inappropriateness of using EL in orienting-response (OR) work (Furedy, 1968) "difficult to evaluate" since my procedure "is entirely different from the one ... [they] have reported and provides, therefore, no real basis for comparison of the data [Fried et al, 1967c, p. 635]." In fact, of course, it is possible to present valid criticisms of claims based on other procedurally different experiments as long as the aspects essential to the argument are replicated. In terms of such essential aspects, I suggest that examination of the three papers (Fried et al, 1966a, 1967a; Furedy, 1968) allows the following fairly easy evaluation of the issue. Fried et al did not replicate the essential aspect, i.e., measuring ECL, of the procedurally different work of investigators (e.g., Allen, Hill, \& Wickens, 1963; Berlyne, Craw, Salapatek, \& Lewis, 1963) whom they criticized. My criticism of Fried et al's work, on the other hand, did replicate the essential aspects, i.e., measuring both ECL and EL, and was therefore relevant in accounting for their failure to find the expected increase in OR to novelty.

In addition to their claim that my criticism is "difficult to evaluate," Fried et al also suggest that it in invalid on the grounds that the more conventionally used ECL measure in OR work is less adequate than their own procedures which concentrate mainly on EL. One shortcoming of ECL as a dependent variable, they feel, is that these transients "have to be expressed in composite curves which average the response measure for considerable numbers of Ss [Fried et al, 1967c, p. 635]." All investigators of electrodermal phenomena would join Fried et al in wishing that our control were sufficient to enable us to do without averaging. However, as an argument for preferring their own procedures over the more conventional procedures, this objection to transient ECL loses much of its force when it is recognized that in their own papers (Fried et al, 1966a, b, 1967a, b, c) the reported EL measures are always based on averaging over "considerable numbers of Ss."

The other shortcoming, according to Fried et al, of previous (unspecified) investigators' use of transient ECL is the adoption of latency criteria for these transients, criteria which are commonly specified in terms of a brief time interval following stimulus onset. This practice is said to be "based on a large number of assumptions, none of which has any empirical basis [Fried et al, 1967c, 
p. 635]." Now, in the first place, it is possible to question whether the particular time interval chosen by an investigator is indeed that which allows the maximal differentiation of the signal (stimulusconnected transients) from the noise (nonstimulus-connected, "spontaneous" transients). However, it is a distortion to suggest that the signal has failed to be detected at a better-than-chance level by investigators who have used some specified time interval (often 1 to 5 sec following stimulus onset) to define their transient ECL, and this is what Fried et al seem to imply when they state that "there is nobasis for extricating the transient change [Fried et al, 1967c, p. 635]." But, more importantly, if Fried et al really feel that such is the case, why do they then go on to making assertions about transients in their own work? They report that their results "indicate a response decrease" in the "transients," as well as making the rather sweeping claim that "decrease of basal level without accompanying decrease in transient is extremely remote and likewise, failure to obtain change in EL also seldom occurs in conjunction with significant systematic change in transients [Fried et al, 1967c, p. 636]." Thus, while other investigators commonly provide latency criteria for their transient ECL measures on $\mathrm{OR}$ work, Fried et al are content to make assertions about transient ECL while providing neither latency specifications, nor any other statistical evidence to support their claims. Their use of ECL in electrodermal OR work, therefore, should be treated with the same sort of skepticism which I have suggested is appropriate for their use of EL in work on electrodermal adaptation.

\section{REFERENCES}

ALLEN, C. K., HILL, F. A., WICKENS, D. D. The orienting reflex as a function of the interstimulus interval of compound stimuli. Journal of Experimental Psy chology, 1963,65, 309-316.

BERLYNE, D. E., CRAW, A., SALAPATEK, P. H., \& LEWIS, J. L. Novelty, complexity, incongruity, extrinsic motivation, and the GSR. Journal of Experimental Psychology, 1963,66, $560-567$.

FRIED, R., KORN, S., \& WELCH, L. Effect of change in sequential visual stimuli on GSR adaptation. Journal of Experimental Psychology, 1966a, 72, 325-327.

FRIED, R., WELCH, L., \& FRIEDMAN, M. Stimulus novelty and intraseries primacy in GSR adaptation. Perception \& Psychophysics, 1966b, 1, 345-346.

FRIED, R., WELCH, L., FRIEDMAN, M., \& GLUCK, S. Is no stimulus a stimulus? Joumal of Experimental Psychology, 1967a, 73, 145-146.

FRIED, R., WELCH, L., FRIEDMAN, M., \& GLUCK, S. The effect of change in sequential visual stimuli on GSR adaptation: II. The novel stimulus as a disinhibiting stimulus. Perception \& Psychophysics, 1967b, 2, 419-420.
FRIED, R., FRIEDMAN, M., \& WELCH, L. High and low anxiety and GSR adaptation. Psychonomic Science, 1967c, 9, 635-636.

FUREDY, J. J. Novelty and the measurement of the GSR. Joumal of Experimental Psy chology, $1968,76,501-503$.

WOODWORTH, R. S., \& SCHLOSBERG, H.
Experimental psychology. London: Methuen, 1954.

NOTE

1. The preparation of this note was facibtated by Grant APA 303-118-80 from the National Research Council of Canada.

\section{Effects of praise and censure on normal Ss' performance on a psychomotor task}

\section{BEVERLEY ROBERTS GOUNARD, I Queen's University, Kingston, Ontario, Canada}

This study investigated performance changes resulting from verbally praising (eight Ss), censuring (eight Ss), or not commenting to (eight Ss) normal Ss as they were engaged in a letter-cancellation task. Censure resulted in significantly faster $(p<.005)$ and better overall $(p<.02)$ performance than praise. Both types of verbal comments produced better overall $(p<.05)$, although not faster, performance than no comments at all. The censured Ss paid for their superiority in terms of a greater number of errors and omissions $(p<.005)$. The differences between the groups were interpreted as resulting from motivational differences.

A cancellation test, in which Ss must cancel out certain letters in a series, represents a classic example of a psychomotor task, i.e., a task "pertaining to the motor effects of cerebral or mental processes [Warren, 1934]." The motor act of cancellation follows perception of the correct stimulus, and thus demands that $S$ adopt a set in a manner analogous to that for a reaction-time test (Yates, 1961). Maximal attention is demanded for best work, and any reduction of attention is reflected directly in the speed or accuracy of the work (Whipple, 1914).

Letter-cancellation tests in the past have been examined for the effects on performance of sex, education (Whipple, 1914), and physical type (Mohr \& Gundlach, 1927;
Klineberg, Asch, \& Block, 1934) but not for the effects of praise and censure. The latter is of interest in considering the effects of social "reward" and social "punishment" in the manipulation of the behavior of individuals engaged in a routine task.

\section{SUBJECTS}

The Ss were 24 female, first-year university students, randomly assigned to the three treatment conditions.

\section{MATERIALS}

Two different pages of typed letters were prepared to form the letter-cancellation test. Twenty-five letters of the alphabet (excluding "Y") were randomly ordered with precaution against the repetition of any letter within two places. Each of the 12 lines of type on each page was composed of 60 consonants and 15 vowels. Each letter was repeated three times in each line of type.

\section{PROCEDURE}

The Ss were tested individually, and after a demonstration, each initially cancelled the vowels on Sheet 1 for a period of $1 \mathrm{~min}$. Before proceeding to Sheet 2, the eight Ss constituting the praised group were told the following: "You seem to be doing very well. Most people don't do half as well as you are doing." Eight others, the censured group, were told: "You don't seem to be doing very well. Most people do twice as well as you are doing." The eight control Ss received no comments on their performance. The comments made in the two experimental groups were designed to be ambiguous as to whether they referred to the Ss' speed or accuracy.

All Ss were then timed for $2 \mathrm{~min}$ as they cancelled the vowels on Sheet 2. By keeping 